\title{
CDISC SDTM Sex of Individual Terminology
}

National Cancer Institute

\section{Source}

National Cancer Institute. CDISC SDTM Sex of Individual Terminology. NCI Thesaurus.

Code C66731.

Terminology codelist used with Sex of Individual within the Clinical Data Interchange

Standards Consortium Study Data Tabulation Model. 